TITLE: RADIOGRAPHIC STUDY OF INFACT IN POL YMER-BONDED EXPLOSIVES

\author{
AUTHOR(S): Erik Fueglso, Q-13 \\ J. D. Jacobson, $\mathrm{M}-4$ \\ Robert R. Karpp, M-4 \\ Russ Jensen, Hercules Corporation, Macna, Utah

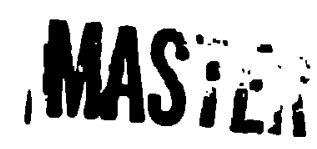
SUBMITTED TO: Conference on Shnsh haves in Condensed Media American Physica: Society
(Fublication)
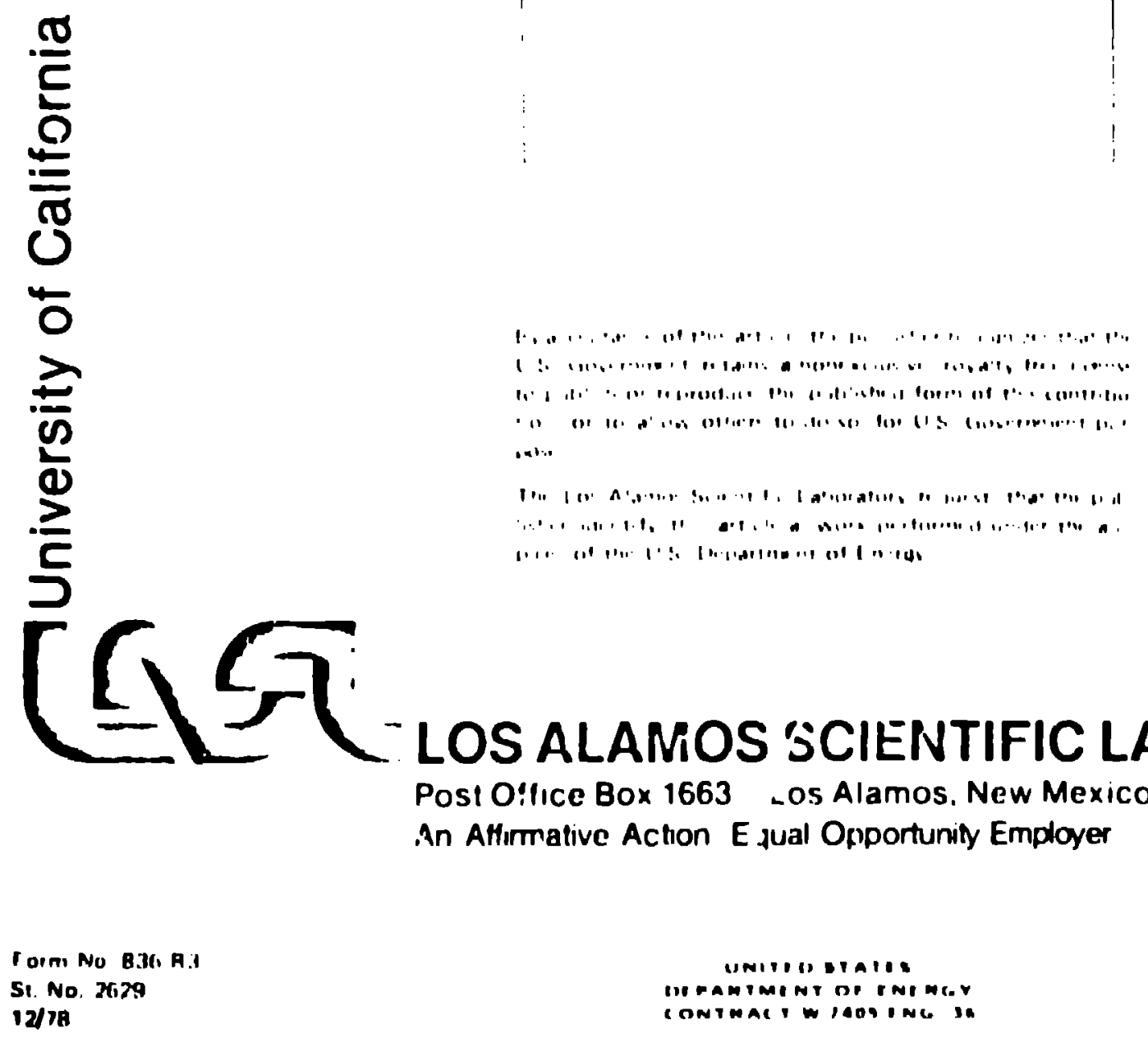

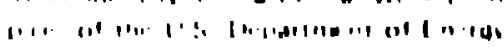




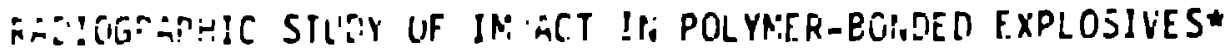

\author{
Erib. Fugelso \\ Jack [. Jacohson \\ Fi:ert R. Käpp \\ Lu ina". s. Aistioral Latreratury \\ brivers ty of California
}

\author{
h.e.s denser \\ bie reilles corperation
}

- Wirk performed under contrace W-7c0!-ENG-36 


\section{RADIOGRAPHIC STUDY OF IMPACT IN POLYMER-BONDED EXPLOSIVES*}

by

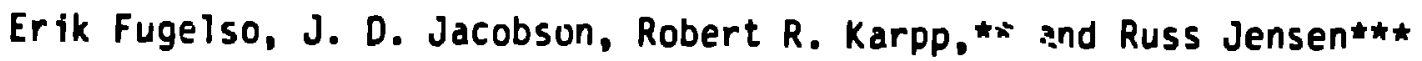

\section{ABSTRACT}

Computer-tomography generated material-density maps from flash $x$-ray radiographs of the impact of cylinders of mockup polymer-bonded explosive (PBX) striking a steel plate. Comparison of the density fields with computer simulation allowed discrimination of rather complex deformation and flow models for insensitive explosives to be used in further studies of chemical reactions in itiated by shock waves.

An initial step to determine the mechanism of detonation inftiation in the ballistic impact of insensitive high explosives is the measurement and computational modeling of the mechanical deformation. To this end, impact paramelers of mochup Polymer Bonded Explosives (PBX) cylinders striki,g a steel plate were mascured through the axisymetric adaptation of computer assisted tonkigraphy (CAT) and compared with several numerical simulations involving diflulelil nuni: ls of the Pl:X. Cl: yetierates a density map throughout the cylinder at stelected tin. inilervals frum low energy ray radiographs. 1,2 Feature.s surh as shock fronts, cracks and recompression zones are ident if led and quanitified. Variations in the mathematical modelling to match early and late time behavior are sumiwhat complex and lead to improved characterization of the Pix mechantcal nodels, to which reactive descriptions can later be applied.

Iwo flash racingrapins frum a set of radlographs of the inpact of an inert PBX mockup on a stecl plate were selecter for study. The projectile was a

Work perforimed under conerace W-7405-ENG-36

* Mos Alarmes National Lahoratory, Los Alamos, NM **Hercules Corporation, Magira, Utah 
right circular cylinder $8.85 \mathrm{~mm}$ radius, $L / D \sim 1.2$, the impact velocity was $677 \mathrm{~m} / \mathrm{s}$. The composition of the cylinder is listed in the table. The $x-r a y$ source was $150 \mathrm{kev}$; radiographic times after initial contact with the steel plate were 4.8 and $11.2 \mu \mathrm{s}$.

The transmitted intensity, an $x$-ray beam through the projectile is related to the incident interisity, $I_{0}$, of the $x$-ray from the source,

$$
\left.\left.1=I_{0} t \int_{0}^{\infty} s(e) \exp \left[-\int_{0}^{L} f(\zeta) v(e, \zeta) d \tau\right] d \epsilon\right) / \iint_{0}^{\infty} s(t) d e\right)
$$

where $\rho(\xi)$ is the material censity, $u(e, 5)$ is the $x$-roy absorption coefficient, which is a function of $x$-ray energy, $e, s(e)$ is the distribution function of the energy of the $x$-ray source and $z$ is the path of the $x$-ray.

Equation (1) reduces to a simple exponential if either $\mu$ is independent of the $x$-ray energy or the $x$-ray source is monochromatic. If the absorption coefficient is not independent of the $x$-ray energy and the source is not monochronatic radiation, it is possiule to calculate an effective constant absorption coefficient through a nonlinear stretching transformation, utilizing the property that the transmitted intensity decreases monotonically with increasing thickness.

In either case the intensity can be written in a simpler form,

$$
[n]=\left(-\operatorname{son}_{0,0} d\right)+[n]_{0} .
$$

The negative logarithm of the $x-r a y$ intensily, after corrections for nonuniforn incident. illtensity and geometric bcam spreading is proportional tu the integral of the product of the material density and the $x$-ray ahsorption coefficient. The pror ile has axisynnetry and, if we select values of this integral on a plane slice perpendicular to the axis of synumtry, flementary application of the techniques of computer assisted tonegraphy will allow reconstruction of the muterial density along the radius. Denote by $g(x)$ the value of the negative logarithm of the $x$-ray at fixced axtal distance, at a distance $x$ frum the axis Denote by $f(r)$ the value of the product an at distance $r$ from the axts. Then 


$$
g(x)=2 \int_{x}^{a} \frac{r f(r) d r}{\sqrt{r^{2}-r_{x}^{2}}} .
$$

where a is some radius beyond which $f(r)$ vanishes. We have measured $g(x)$ and can calculate numerically the value of $f(r)$.

The two radiographs were digitized on a PDS icanning microdensitometer at 50 micron spacing with a 50 micron by 50 micron aperture; 5121 ines with 10c 4 pixels per line were obtaines. Figures 1 and 2 show the digitized radiographs.

These radiographs were then displayed on the Cointal 8000 digital image display and an interactive program was utilized to deiermine the centerline of the projectile. The maximun tilt of the projectile from ideally normal impact was measured and was less trian $2^{\circ}$. The needed projecticns were then extracted from the digitized radiograph.

To reduce film grain noise, a median or Tukey filter was used on each line. Figure $3 a$ shows one line of the crigitial input data of the 4.8 us radiograph wi:h film noise. This line is near the top of tha projectile (atout ten lines below the top). The median filter was appliad to this line, its negative logarithm then taken and then corrected for the polychromatic source.

The $x$-ray ahsorption coefficient for this material in the ringe of the incident $x-r a y$ spectrum ts essentially indepenaent of $x$-ray ener: $y{ }^{3}$ therefore, this effect of beam hardening is small. The intensity outsid? the projectile iniage is nearly constant throughout this line and throughour the ent ire baicugrapl and was subtracted fron: the ent ire diaitized projiction. Thi resulting projertion was then inverted numerically line by line to give the material den';ity along that line (Fig. $3 b$ ).

Since thce expected variation of density in a shock wave or rarefaction wave is of the order of $0.5 \%-10 \%$, the inlages werc enlianced by a linear stretch frum. 87.52 peak density to 100x peat density in eight grey level increments (iigs. 4 and 5 ). Cach gycy level represents a 1. stiz rolative density ster in an/p. This cenhancennent brings out signifliant detail. In the 4.8 us picture, a slightly curved shockwave is visible near the top of the projectile and a ratefation wave is see!l to extens frum the intersection of the shorkwave and the outer edge to the axts and then cont inues on from the axis (in the picture this looks as if the wave reflects from the axis!. There is also an annular high comiression zore whose center is at the intersection of the edye of the projectile and the plate. A fine resolut fon enhancencent slionied a 
very narrow ridge of slightly higher density extending from the center recompression zone. Higher density regions appear behind the top shock and the reflected rarefaction. Densities in the spray are very low. The enhanced picture for the $11.2 \mu \mathrm{m}$ radiograph shows no definable wavefronts, but shows a pronounced density structure. The recompression zone has shifted towards the axis. A different enharicement, concentrating on lower densities, show's a narrow crack extending from the center line and bounding the lower density bubble.

The density fields obtair.ed from radiographs can be compared to those obtained from computer simulations and the adequacy of the assumed material response functions judged from the extent of agreement. A Lagrangian prograr (SALE), using artificial viscous pressure in the shock, gave the solutions shown in Fig. 6 and 7 for a simple fiuid model in symmetric impact $(677 \mathrm{~m} / \mathrm{s})$. In this calculation the pressure is given by the Mie-Gruneisen form referred to the shock Hugoniot, tut modified to give negligible rupture strength.

The prominent features of the radiographs appear also in the simulation: the inital shock $(21 \mathrm{~kb})$ rapidly attenuated by lateral expansion, followed by jetting ano a recompression to near the stagnation pressure $(5 \mathrm{~kb})$, beginning riear the periphicry and converging to the center, finally producing at the impact face a disc of warri. miaterial at normel density and, at the back face, a dome of spalled material at lc.s density. Some details of the simulations are less plausible and would be regarded as numerical artifacts were they nout pres: cut also in thr recalun ra!tiographs: the slightly higher density at the ceriter of the lind d.t $f$ ace and the shell of normal density material rising from the compincted disc near the edge. The recompression is of particular interest in this systen, hecause it has bech proposed as a trigger for the delayed detonation fften otiserved in propellants under these condtions. 
TABLE I

COMPOSITION BY WEIGHT OF THE INERT POLYMER-BONDED

EXPLOSIVE (PBX) MOCKUP CYLINDERS

Constituent

Cross linked polymers

Plasticizer

Powdered Alum?num ( 5 um)

Talc

Salt $\left(100 \mu n_{i}\right)$

Salt $(50 \nu \mathrm{m})$
Wt.\%

19.00

10.00

19.50

14.12

17.38

20.0

\section{REFERENCES:}

1. Kruger, R. P., G. W. Weckst 19, and Morris, R. A., "Industrial Applications of Comifuted Tomography at Los Alamos National Laboratory" Optical Engineering, 19, 273-282, (if80).

2. Fugelso, E, "Material Density Measurements from Dynamic Test X-ray Fadiographs Using Axisymmetric Tomography," Los Alamos Sc ientific Laboratnry, LA-EïE5-NS (1981).

3. Seigbahn, K., c... Algha, Br.ta and Gamina Ray Spectroscnpy, Vul. I, North H(1)ar.. iluces). 


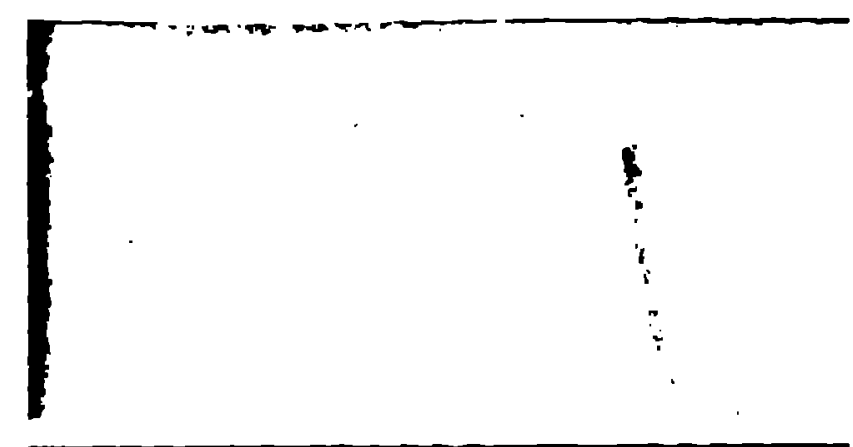

Fig. 1. Digitized radiographic of the mockup $P B X$ cylinder striking a steel plate at 4.8 usec after impact. Striking velocity is $677 \mathrm{~m} / \mathrm{sec}$.

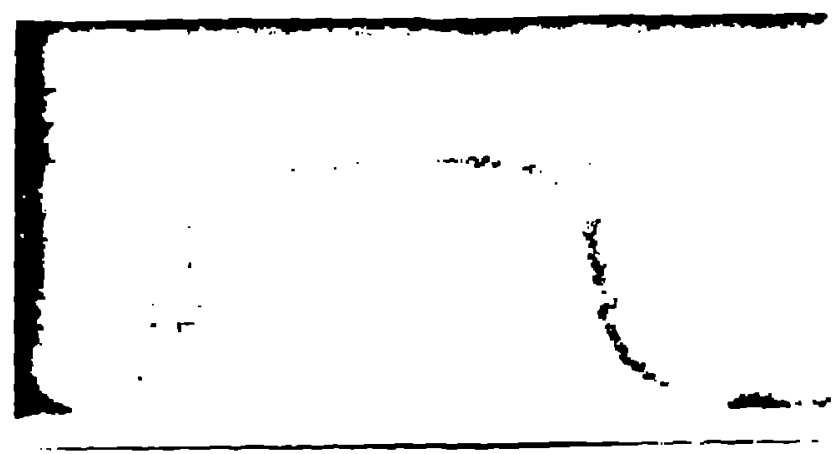

Fig. 2. Digitized radiograph of the mockup PBX cylinder striking a steel plate at $11.2 \mu \mathrm{sec}$ after impact. Striking veloc:ty is $677 \mathrm{~m} / \mathrm{sec}$.

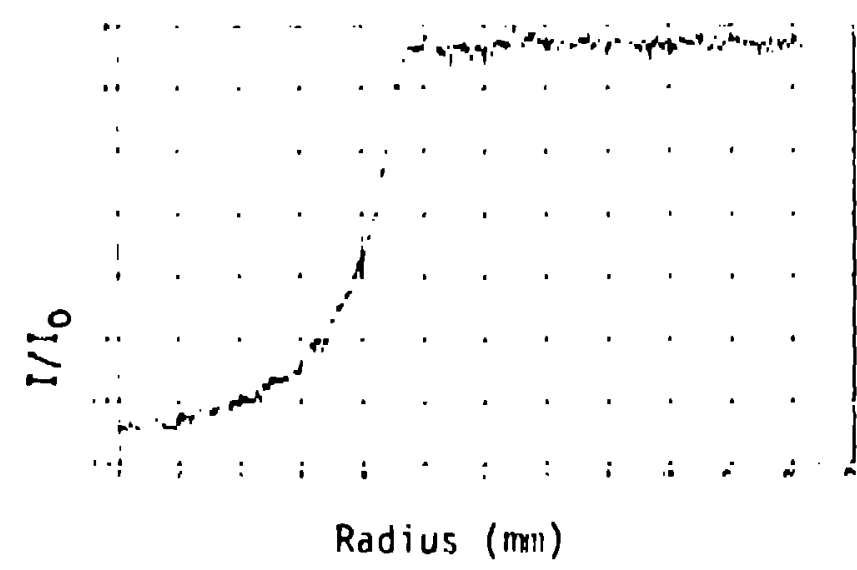

Fig. 3a. Radiographic film density versus radius for one line of the scanned data $1 \mathrm{~mm}$ from the top of the projectile. Timc of radiouraph is $4.8 \mathrm{usec}$.

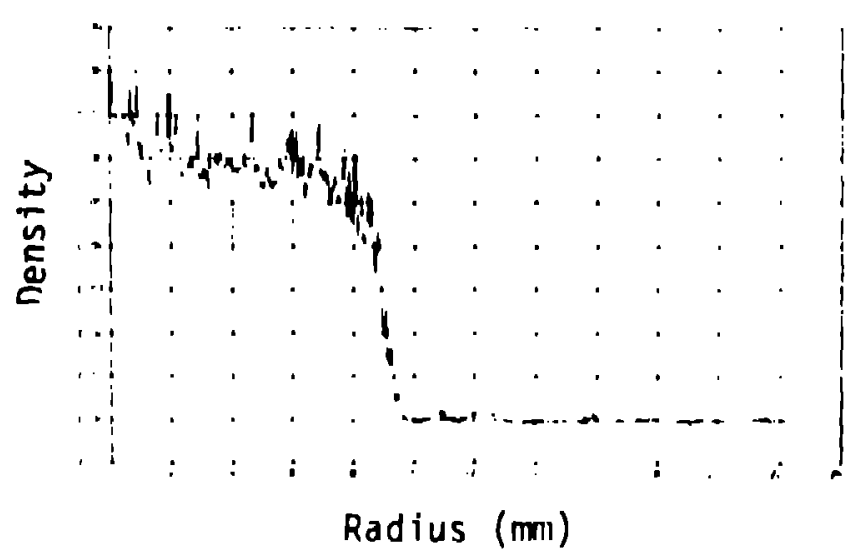

Fig. 3b. Reconstruction of the density profile as a function of radius. 


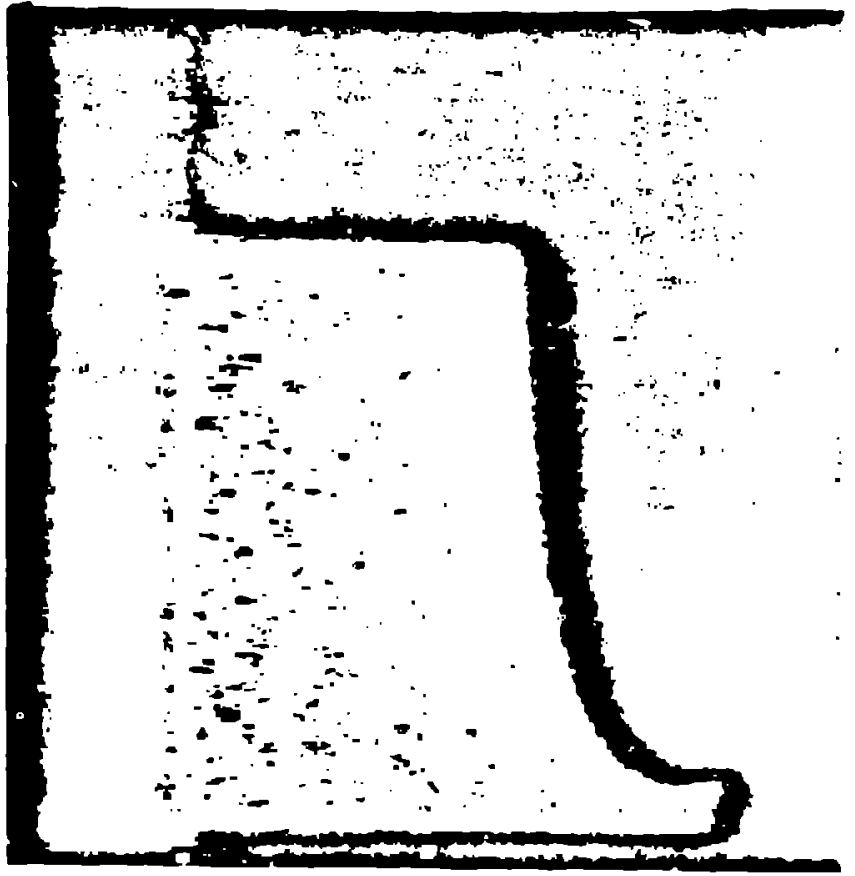

Fig. 4. Enhanced image ( 1 inear stretch) for the projectile at 4.8 usec after impact. A shock wave and two rarefaction waves are now visible.

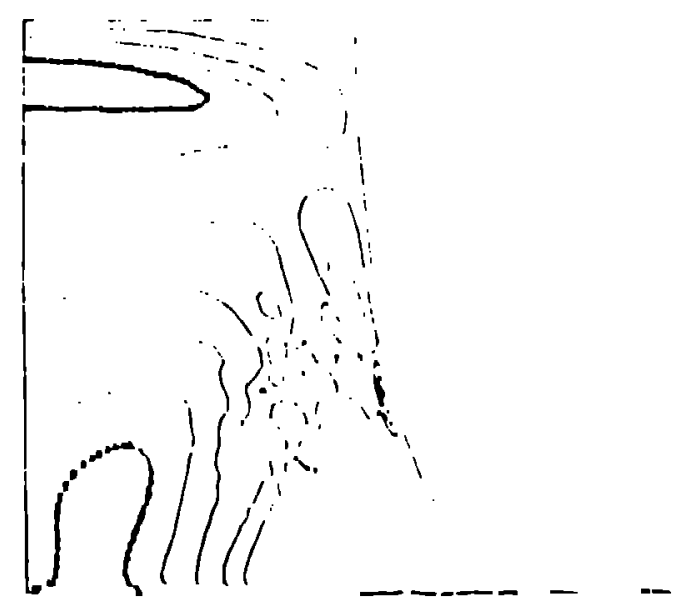

Fig. 6. Calculated density contours for imparl of a mockup P'BX cylinder striking a stecl plate at $677 \mathrm{~m} / \mathrm{s}$ at $6.0 \mathrm{~ms}$ after impact. Maximum and minimuli density ratios are 1.140 and 0.815 . Density contours are 0.033 .

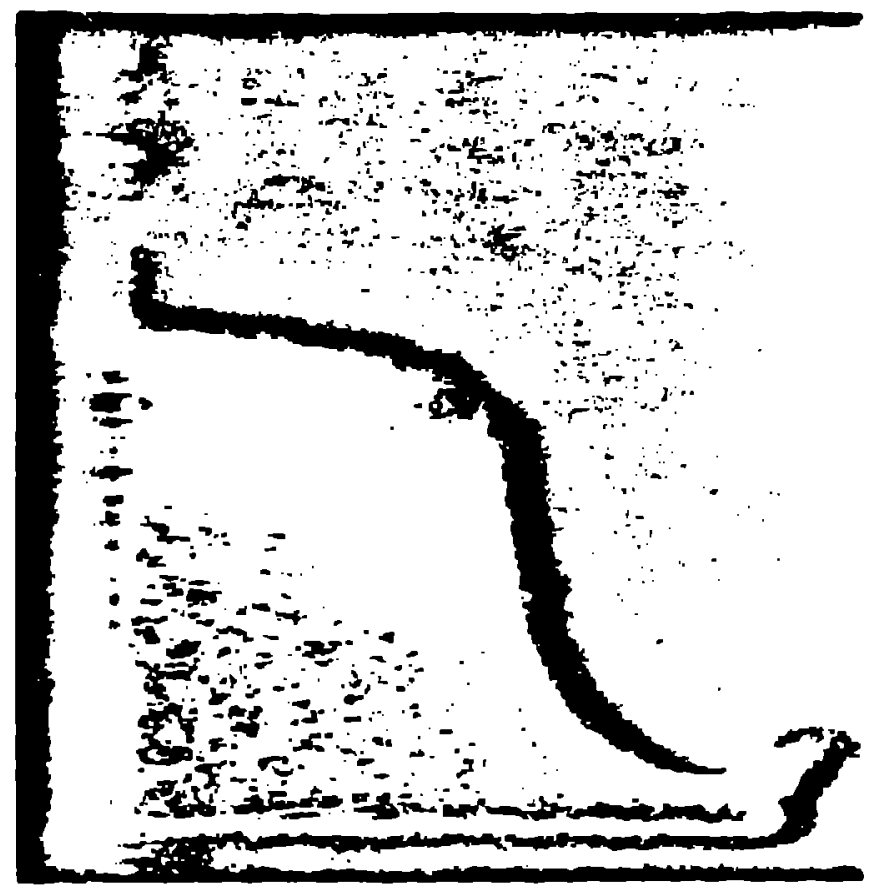

Fig. 5. Enhanced image ( 1 inear stretch) for the projectile at $11.2 \mu \mathrm{sec}$ after impact. No specific wavefront structure is visible, but the density gradients are quite pronounced.

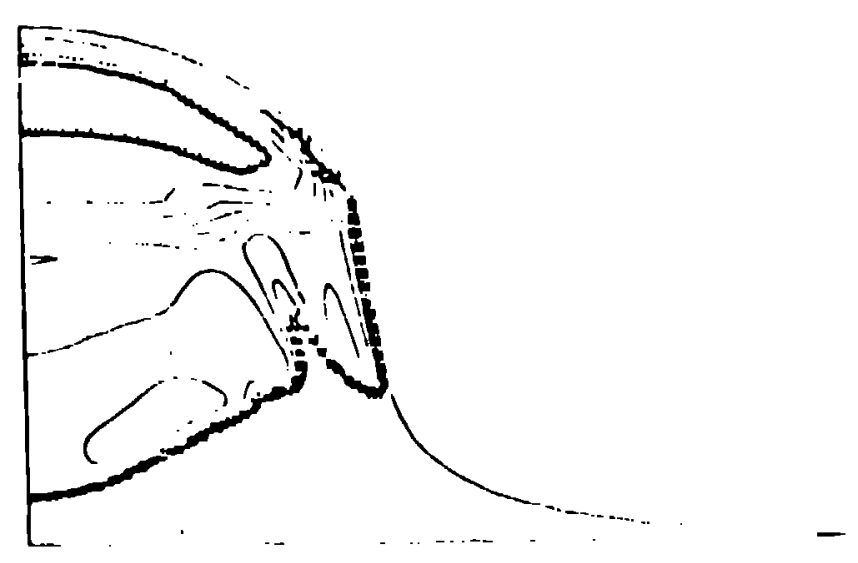

Fig. 7. Calculated density contours for impact of a mockup of PBX cylinder. striking a steel plate at $677 \mathrm{~m} / \mathrm{s}$ at 12.0 ms after impact. Maximull and minimum density ratios are 1.027 and 0.304 . Density contours are .073 . 